\title{
Experimental Study on Energy Dissipation Optimized Damping Arrangement of L-Eccentric Structure with Viscous Dampers
}

\author{
Guojing $\mathrm{He}$, Lin Tu , Aijun Chen and Xiaomei Jiang \\ (College of Civil Engineering and Mechanics, Central South University of Forestry and Technology, \\ Changsha, 410004, China) \\ Email:752631468@qq.com
}

\begin{abstract}
Keywords: Viscous damper, L-shaped eccentric structure, arrangement location of damper
Abstract. Viscous damper is a kind of velocity-related damper without rigidity. It can dissipative seismic energy and also can effectively reduce vibration of the structure .In this paper, a dynamic experiment for L-shaped eccentric structure was carried out to compare and verify seismic energy dissipation effect under seismic excitation with viscous damper. A 4-layer L-shaped eccentric structure with and without viscous damper under seismic excitation has been analyzed by Finite element method, and through the model test to validate it. From the comparative analysis, under seismic excitation the torsion of the eccentric structure is significant. Compared with no damper eccentric structure, the dissipation performance of the eccentric structure with damper is more obvious. Different arrangement of the dampers affect the eccentric structural damping effect. For L-shaped eccentric structure with damper, Should find the best arrangement location of damper to confirm optimal control. Through this study, provide a theoretical basis and reference for the eccentric structure in practical engineering.
\end{abstract}

\section{Introduction}

With the rapid development and urbanization of the national economy, more and more novel architectural style, building functional complex and changeable. Internal functional requirements is also rising, in order to meet building functional complexity and diversity, eccentric structure in large numbers.

In the earthquake, eccentric structure will not only have translational but also have reversion[1] ,thus exacerbating the structural damage, the one of the main earthquake excessive torsional seismic response leading to structural seismic performance degradation, accelerated structural damage and even collapse[2]. Adjusting the layout of structure and the increasing torsional stiffness is the traditional design methods, the traditional design methods can not be a good solution to the problem of torsional vibration of eccentric structures under earthquake. Due to imperfect design theory and methods, the eccentric structure with damper damping evenly effect is not ideal, has seriously hampered the development of new structural system. To this end, the eccentric structure reasonable energy dissipation damper settings, the use of modern control theory and methods to reduce torsional seismic response of eccentric structure[3].

Taking L-type eccentric structure of a 4-layer for example, using the finite element analysis software sap2000 model structure and calculate the seismic response of the models in the seismic intensity, obtained dynamic characteristics corresponding calculated values, and use the shaking table test study to validate it[4].

\section{The objective function}

When viscous damper position optimization, optimization of structures with different objective functions. In this paper, the following three eccentric structure using an objective function.

Maximum acceleration as the target function

Wherein, a is maximum acceleration of selected i-layer structure. function

Interlayer displacement angle and displacement ratio as a weighted combination of the objective 
Wherein, $\alpha, \beta$ is the weights, the interlayer displacement angle right weight coefficient $\alpha$ as the main factor, here take $\alpha=0.7, \quad \beta=0.3$. $[\Delta \theta]=1 / 550$, "Seismic Design of Buildings"(GB50011-2010), The limits of elastic displacement angle of the frame structure, $[\Delta \delta]$ $=1.2$,"Technical specification for concrete concrete high-rise building"(GB50011-2010), The limits of structural displacement ratio [5].

Displacement ratio between layers as the objective function

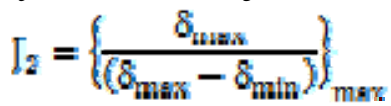

\section{Shaking table test [6]}

Making a ratio of $1: 15$ scale model, story is $280 \mathrm{~mm}$, The total height is $1.12 \mathrm{~m}$, Column size is $30 \mathrm{~mm}$ $\times 30 \mathrm{~mm}$,Beam size is $33 \mathrm{~mm} \times 15 \mathrm{~mm}$, Slab thickness is $8 \mathrm{~mm}$, Material is plexiglass, The adhesive mode of the model framework structure is consolidation. The test has been finished at Hunan University of Science and Technology Laboratory, Model dimensions shown in Figure 1, Designed the installation dimensions shown in Figure 2.

Considering all factors, similar to the relationship between model and prototype structures ( similarity coefficient $=$ model parameters $/$ prototype parameters) as follows.

1. Length $\mathrm{SL}=1 / 15$ 2. Elastic Modulus $\mathrm{SE}=0.0743 \quad 3$. Acceleration $\mathrm{Sa}=2.42$ 4. Density $\mathrm{S} \rho=0.462$ 5. Time $\mathrm{St}=0.166$ 6. Quality $\mathrm{Sm}=1 / 7312$ 7. Stiffness $\mathrm{Sk}=4.953 \mathrm{E}-03 \quad$ 8. Stress $\mathrm{S} \sigma=0.0743$

9. Structural damping $\mathrm{S} \zeta=1$ 10. Damp $\mathrm{Sc}=8.25 \mathrm{E}-4$ 11. Frequency $\mathrm{S} \omega=6.024$ 12. Linear displacement $\mathrm{Sx}=1 / 15$
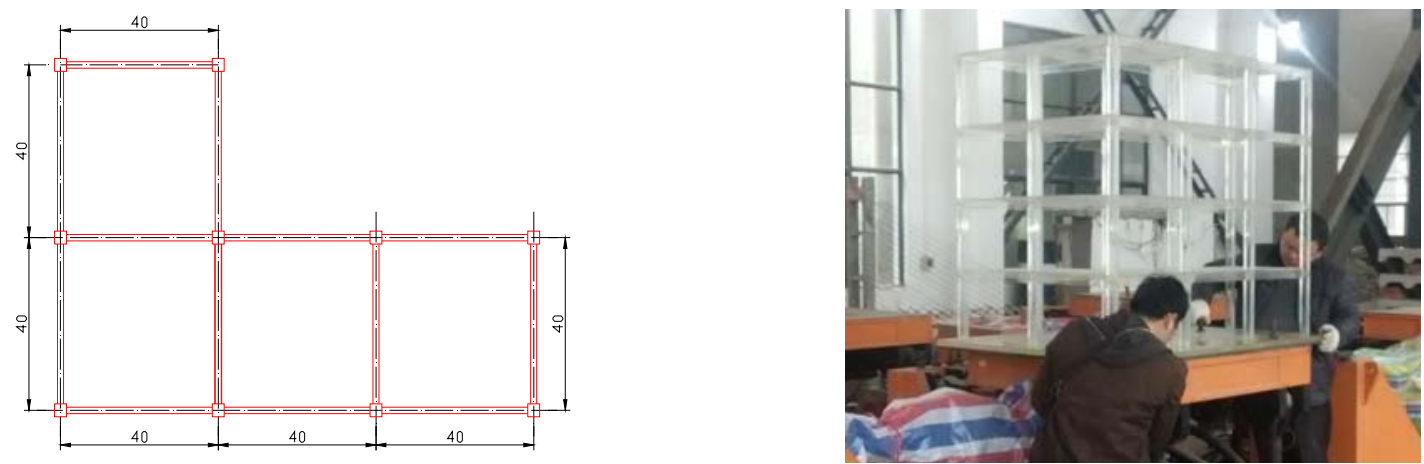

Figure 1 model structure plane size (unit: $\mathrm{cm}$ ) Figure 2 Designed the installation dimensions

Shaking table tests conducted more earthquake, basic intensity earthquake, rare earthquake stage. The test uses an artificial seismic wave field and two real strong motion records (El-Centro wave, Taft wave).

In this experiment, a total of four operating conditions were measured: (1) no control; (2) Control 1; (3) Control 2; (4) Control 3. Four different plan are shown in Figure 3 to Figure 6.

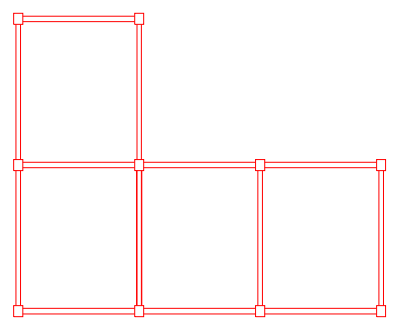

Figure 3 uncontrolled

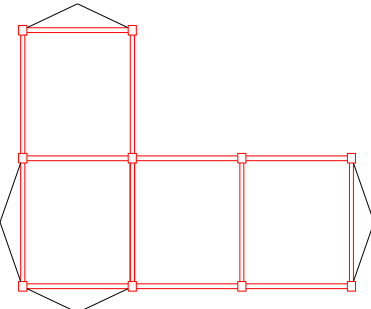

Figure 4 Controlled 1

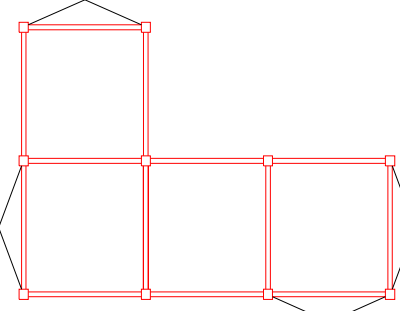

Figure5 Controlled

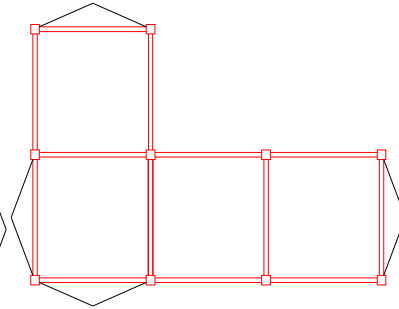

Figure 6 Controlled 3 
Dynamic Response Analysis

Natural cycle

Table 1 Structure Model Cycle

\begin{tabular}{|l|l|r|r|r|r|r|r|r|r|r|r|}
\hline \multicolumn{2}{|c|}{} & 1 & 2 & 3 & 4 & 5 & 6 & 7 & 8 & 9 & 10 \\
\hline \multirow{3}{*}{ Uncontrolled } & Theoretical value & 0.1144 & 0.1131 & 0.1062 & 0.0352 & 0.035 & 0.0327 & 0.0194 & 0.0187 & 0.0175 & 0.0136 \\
\cline { 2 - 11 } & Found & 0.1099 & 0.1085 & 0.9438 & 0.0321 & 0.032 & 0.0309 & 0.0176 & 0.0167 & 0.0154 & 0.0112 \\
\hline \multirow{3}{*}{ Control 1 } & Theoretical value & 0.1205 & 0.1156 & 0.1103 & 0.0467 & 0.041 & 0.0398 & 0.0225 & 0.0200 & 0.0199 & 0.0155 \\
\cline { 2 - 11 } & Found & 0.1167 & 0.1129 & 0.1056 & 0.0321 & 0.030 & 0.0287 & 0.0206 & 0.0167 & 0.0159 & 0.0141 \\
\hline \multirow{3}{*}{ Control 2 } & Theoretical value & 0.1259 & 0.1209 & 0.1079 & 0.0567 & 0.049 & 0.0408 & 0.0265 & 0.0194 & 0.0188 & 0.0145 \\
\cline { 2 - 12 } & Found & 0.1198 & 0.1147 & 0.0986 & 0.0478 & 0.045 & 0.0385 & 0.0231 & 0.0167 & 0.0155 & 0.0129 \\
\hline \multirow{2}{*}{ Control 3 } & Theoretical value & 0.1132 & 0.1109 & 0.0978 & 0.0330 & 0.031 & 0.0299 & 0.0234 & 0.0204 & 0.0165 & 0.0119 \\
\cline { 2 - 11 } & Found & 0.1005 & 0.0987 & 0.0866 & 0.0302 & 0.027 & 0.0261 & 0.0208 & 0.0183 & 0.0149 & 0.0092 \\
\hline
\end{tabular}

By the Table 1 can be found in the absence of the model structure and a different arrangement of the damper control damper control cycle and frequency change little before 3 model cycle and frequency difference of no more than 0.2. As can be seen from the table, only the structure due to viscous dampers provide viscous damping, does not provide stiffness, mainly through increasing the structural damping ratio, through dampers to energy, rather than by changing the structure of the natural cycle, to reduce the structure under earthquake dynamic response.

Displacement ratio
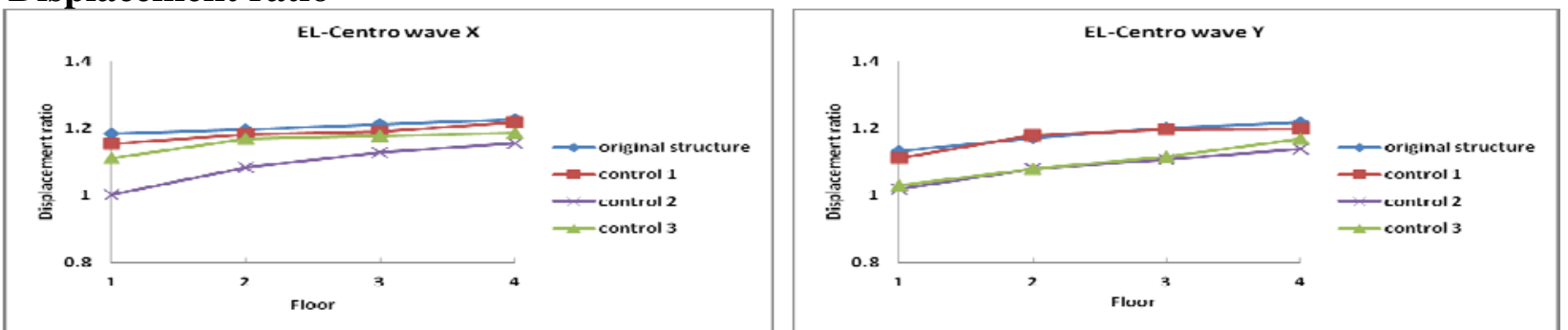

Figure 7 EL-Centro wave $\mathrm{X}$ to displacement ratio Figure 8 EL-Centro wave Y to displacement ratio

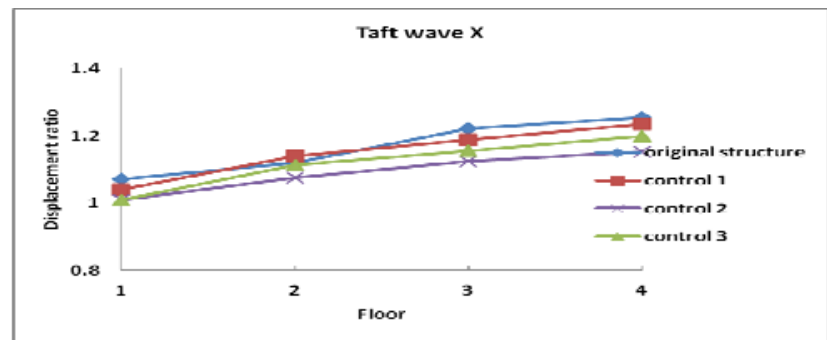

Figure 9 Taft wave $\mathrm{X}$ to displacement ratio

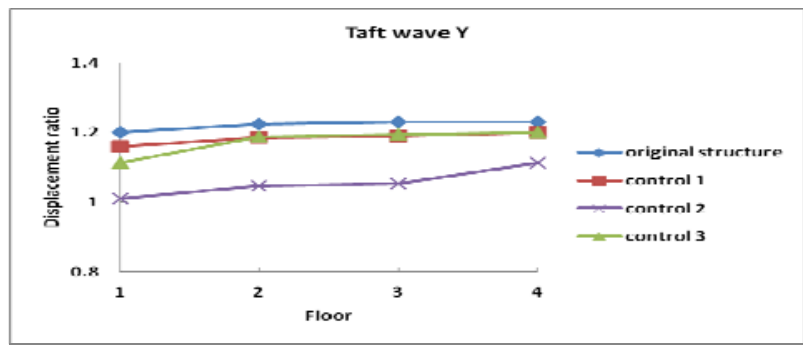

Figure 10 Taft wave $\mathrm{Y}$ to displacement ratio

From Fig7 to Fig10 can be seen: not added viscous dampers, structural displacement than the maximum reached 1.254, 1.2 larger than the specification requirement. After setting damper, effectively reduces the displacement ratio structure such that the structure of the layers have been reduced displacement ratio varying degrees, after the basic damping displacement ratio can be controlled in the range of 1.2. Different layout scheme damper damping effect of different structures, different arrangements damper damping effect at different seismic intensity are also different from the tables and graphs can be drawn layout program two better than the other two programs, the damping effect more apparent. 


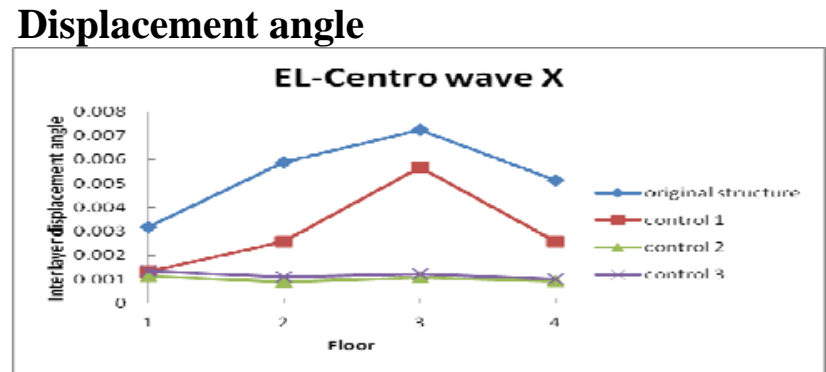

Figure 11 EL-Centro wave $\mathrm{X}$ the interlayer displacement angle

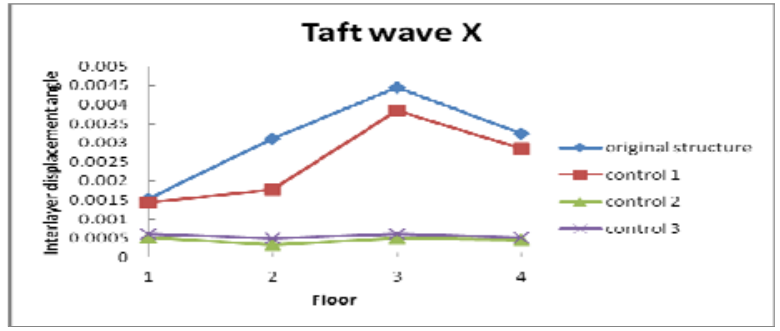

Figure 12 Taft wave $\mathrm{X}$ the interlayer displacement angle

From Figure 11- 12 can be seen: at each earthquake, the maximum angular displacement between the structural layer occurred in the third layer, layer displacement angle between the original structure does not comply with section "seismic design of buildings" requirement, structural parts interlayer displacement angle is greater than 1/550, after viscous dampers, angular displacement between the layers of regulatory requirements are met. Under different circumstances viscous dampers arranged at different seismic intensity, the structure of the inter-story drift control to varying degrees, with Option II (inter displacement ratio and drift angle weighted combination) optimal control. It can be seen not only viscous dampers can effectively control the reverse effect of the structure, and can effectively control the level of structural deformation.

\section{Conclusion}

Structure under viscous dampers and damper arrangement position is not changed little arrangement affect the structure of the self-oscillation period, an increase of viscous dampers damping structure, mainly by increasing the structural damping ratio, energy consumption by dampers rather than by changing the structure of the natural cycle, to reduce the structural dynamic response under seismic action.

By analysis of knowledge, the original structure displacement ratio does not meet specifications. After viscous dampers, effectively reducing the dynamic response of the structure, making the structure to meet regulatory requirements. Description damper can play to reduce the displacement ratio, control structures reverse reaction.

From the above results of these analyzes, we can know that in viscous dampers optimized arrangement to displacement ratio and inter-story drift control function is a weighted combination of sequential search method is the best arrangement of the combined effect of an optimized arrangement, it in the structure of each project objective control can go almost the best control effect.

\section{Acknowledgements}

The research described in this paper was under the support of the Theoretical and applied basic research on the optimization design of the energy dissipation of eccentric structure (NSFC Project No.51178473 ) and that was under the support of the Graduate student science and Technology Innovation Fund of Central South University of Forestry and Technology(No.CX2014Z46)

\section{References}

[1] Jianbao Li, Xinlin Lv, etc. Shaking table tests on a single tower structure overall model simulations Beijing LG Building, Building Structures.2006,27(2).

[2] Feng Yan, Xinlin Lv. RC frame vibration table test of comparison with and without supplemental viscous damping walls [J]. Journal of Building Structures,2005, Vol.26(5):8-16.

[3] Zhongxian Li, yu ao He. Optimization of high-rise buildings in the earthquake response of the damper control [J]. Journal of Building Structures, 1994,15(4):53-61. 
[4] Zhongxian Li, Shou ze Xu. Tall Buildings horizontal seismic response damper control theory and experimental study [J].Earthquake Engineering and Engineering Vibration,1994,14(3): 97-104.

[5] Zhongxian Li, Jia Wan, Xinliang Jiang. Tall Building torsion coupling seismic response control damper Experimental Research of Vibration Engineering,1999,12(2):262-266

[6]Bolong Zhu, Xinlin Lv. Vibration table test Earthquake Engineering and Technology of China four decades Beijing: Seismological Press,1989. 